\title{
Community-Based Social Marketing: Effects on Social Norms
}

\begin{abstract}
Purpose: This research investigates whether application of a community-based social marketing principle, namely increasing the visibility of a target behaviour in the community, can change social norms surrounding the behaviour.

Design/methodology/approach: A repeated measures quasi-experimental design was employed to evaluate the Victorian Health Promotion Foundation's Walk to School 2013 programme. The target population for the survey were caregivers of primary school children aged between 5-12 years old. The final sample size across the three online surveys administered was 102 respondents.

Findings: The results suggest that the programme increased caregivers' perceptions that children in their community walked to and from school and that walking to and from school is socially acceptable.

Originality/value: The study contributes to addressing the recent call for research examining the relationship between community-based social marketing principles and programme outcomes. Further, the results provide insight for enhancing the social norms approach, which has traditionally relied on changing social norms exclusively through media campaigns.
\end{abstract}

\section{Keywords}

Social norms, social marketing, community, children, walking

\section{Article classification}

Research paper 


\section{Community-Based Social Marketing: Effects on Social Norms}

\section{Introduction}

The World Health Organisation (WHO) recommends that healthy children and teenagers 517 years old accumulate a minimum of 60 minutes of physical activity each day (WHO, 2015). Physical activity provides children with a wide range of benefits to their musculoskeletal tissues, cardiovascular system and mental health, and further supports development in areas such as confidence and social skills (ibid.). Data from countries like the United States and Australia, however, indicate that few children and adolescents engage in the recommended level of physical activity and that physical activity rates decline with age (Department of Health, 2014; Troiani et al., 2008). For instance, findings from the Australian Health Survey 2011-2012 indicate that only a third of Australian children meet the WHO standard and that sedentary forms of activity increase (e.g. watching TV) and physical activity decreases with age (Department of Health, 2014). One of the main consequences of insufficient physical activity is obesity, and obese and overweight children face an increased risk of morbidity even if they maintain a healthy weight later in life (Deckelbaum and Williams, 2011). It is thus vital that low levels of physical activity are addressed early during childhood (Shonkoff et al., 2009).

Walking to and from school represents an efficient way to increase levels of regular physical activity among children owing to the behaviour's low cost and almost universal accessibility (Rosenberg et al., 2006). Walking can be integrated into daily routine by many families with school-age children (Brophy et al., 2011). A systematic review of programmes for promoting active transport, such as walking, to school across the United States, Australia and the United Kingdom indicated that the characteristics of effective programmes included use of policy and events to achieve change (Chillón et al., 2011). A more recent review of active school travel programmes further indicated that addressing safety concerns and individual family lifestyle needs are vital to maximising programme effectiveness (Reynolds et al., 2014). Nevertheless, while walking was the most promoted form of active transport, the majority of the programmes were only marginally effective, indicating that further research is warranted (Chillón et al., 2011). This need for additional research is amplified by the increasing prevalence of inactive modes of travel to and from school, while active transportation including walking is on the decline in countries like the United States (McDonald, 2007) and Australia (van der Ploeg et al., 2008). This decline is considered at 
least partly attributable to social norms surrounding 'good parenting' (Foster et al., 2014), with driving children to and from school considered safer and thus more socially responsible (Lorenc et al., 2008). Research shows that caregiver perceptions of few other children in the neighbourhood walking to and from school (Chillón et al., 2014; Timperio et al., 2006), as well as beliefs regarding the social acceptability of this behaviour (McMillan, 2007; Panter et al., 2010; Schuster et al., in press), significantly inhibit this form of active transportation. Walking rates could thus be improved through approaches that act upon caregiver perceptions of these descriptive and injunctive social norms respectively (Lorenc et al., 2008).

Two important behaviour change frameworks that target social norms are the social norms approach (SNA) and community-based social marketing (CBSM). The SNA corrects misperceptions about, or increases the saliency of, social norms surrounding the target behaviour (Burchell et al., 2013). That is, SNA campaigns leverage individuals' tendency to act in accordance with others by telling the target audience, typically through traditional media, about the behaviour of others (Burchell et al., 2013; McKenzie-Mohr and Schultz, 2014). SNA campaigns, however, have had mixed success (Burchell et al., 2013; Schultz et al., 2007). Kallgren et al. (2000) proposes that SNA campaigns are more successful when messages and associated stimuli (e.g. walking to and from school behaviour) are visible in the community. A key principle of community-based social marketing is to increase the visibility of behaviour in the community (Lynes et al., 2014; McKenzie-Mohr, 2011; McKenzie-Mohr and Schultz, 2014). However, empirical research is needed to investigate the efficacy of this principle, together with the other principles of CBSM (Lynes et al., 2014).

The present research examines whether the application of a CBSM principle, namely increasing the visibility of behaviour in the target audience's community, can change social norms surrounding a behaviour using a repeated measures quasi-experimental design. Accordingly, this research makes three primary contributions to the literature. First, it extends research assessing the impact of CBSM principles on programme outcomes, an underresearched domain (Lynes et al., 2014). Second, the research provides insight for enhancing the SNA, which has traditionally relied exclusively on communicating social norms through media campaigns. Third, it contributes to addressing the call for more rigorous evaluations of social marketing programmes (Evans et al., 2014). Practically, this study will provide improved understanding of how CBSM can be employed to influence social norms, often important determinants of behaviours targeted by social marketing. To accomplish these aims, this research investigates the impact of the Victorian Health Promotion Foundation's (VicHealth) Walk to School 2013 programme on social norms surrounding walking to and 
from school behaviour. Walk to School 2013 encouraged primary school children in Victoria to walk to and from school every day during the month of November, 2013. The programme aimed to raise awareness of the physical, environmental and social benefits of active transport (walking to and from school), and encourage primary school children walk to and from school more often. An outcome for parents and children participating in Walk to School 2013 may be increased visibility of walk to school behaviour, which is the focus of the current study.

\section{Social Norms and the Social Norms Approach}

Social norms theory seeks to influence behaviour by altering perceptions of what is considered 'normal' behaviour (Burchell et al., 2013). Social norms comprise descriptive norms, the extent to which individuals perceive that others perform a behaviour, and injunctive norms, individuals’ perception of whether others approve or disapprove of a behaviour (Cialdini et al., 1990). In the research context, descriptive norms would constitute the extent to which individuals perceive that other children walk to and from school, while injunctive norms would encompass perceptions of whether others approve or disapprove of children walking to and from school. Both types of norms have been shown to be instrumental in determining whether caregivers permit their children to walk to and from school (Chillón et al., 2014; McMillan, 2007; Panter et al., 2010; Schuster et al., in press; Timperio et al., 2006).

Interventions based on social norms theory attempt to challenge the norms held by the target audience, and motivate and direct behaviour on the basis of individuals' tendency to conform (Schultz et al., 2007). That is, campaigns employing the social norms approach (SNA) typically inform the target audience about the behaviours of people that are similar to them, traditionally through mass media (Burchell et al., 2013; McKenzie-Mohr and Schultz, 2014). Two of the main problems that the SNA attempts to challenge are pluralistic ignorance (Thaler and Sunstein, 2008) and false consensus (Ross et al., 1977). Pluralistic ignorance is a form of misperception in which a majority of people reject a norm in private, but incorrectly believe that others approve of it, leading them to engage in the behaviour that represents the perceived social norm. Further, long-term SNA aims to reduce a false consensus effect, in which individuals overestimate the prevalence of some behaviours (Ross et al., 1977), such as the proportion of parents driving their child(ren) to and from school. According to the SNA, providing parents with messages informing them about the social acceptability and 
prevalence of behaviours like walking to and from school may help correct misconceptions and establish walking as the perceived norm.

The use of the SNA in social marketing has attracted significant attention of late (see for example Burchell et al., 2013). Burchell et al. (2013) suggest that successful social norms campaigns tend to have four main characteristics: good use of marketing, use of reference groups appropriate for the target audience, credibility and avoidance of promotion of negative behaviour as a possible side effect. The SNA has been primarily employed in the context of substance abuse (cigarettes, alcohol and drugs), particularly among university students (e.g. Gomberg et al., 2001; Mattern and Neighbors, 2004; Murphy et al., 2012), although recently it has been applied to other domains such as environmental behaviours, violence prevention, road safety and bullying (Burchell et al., 2013). SNA campaigns, however, have had mixed success (Burchell et al., 2013; Schultz et al., 2007). For instance, while Perkins and Craig (2002) report a 21\% decrease in drinking among first year university students owing to a campaign based on the SNA, Thombs et al. (2004) reported no change in perceived drinking norms or alcohol consumption although $66.5 \%$ of the students were aware of the campaign.

An experiment conducted by Schultz et al. (2007) provided a possible explanation for the mixed effects of SNA campaigns. As many of social norms campaigns use mass media, they are likely to reach different groups of individuals: those whose behaviour is less desirable than the norm and those whose behaviour is more desirable than the norm. While the former group may modify their behaviour for the better, Schultz et al. (2007) observed that the latter can lower their engagement in the positive behaviour to match the norm. Including both descriptive and injunctive messages may help overcome the negative influence of social norms campaigns (Schultz et al., 2007). Kallgren et al. (2000) proposed that SNA campaigns tend to be more successful when messages and associated stimuli (e.g. walking to and from school behaviour) are visible in the community and increase the salience of the positive behaviour. Another key determinant of campaign success is the perceived credibility of the social norm being publicised (Burchell et al., 2013). In one unsuccessful campaign, it was found that $45 \%$ of the participants did not believe the social norm data (Granfield, 2002). Ensuring the perceived credibility and believability of the social norm being promoted and increasing visibility of the desired behaviour are thus important factors influencing the success of the SNA. 


\section{Community-Based Social Marketing}

Rather than telling the target audience through media about others' behaviour via a SNA, increasing the visibility of the behaviour by providing opportunities for the target audience to witness others' performing the behaviour or be exposed to the behaviour through noticeable prompts (Lynes et al., 2014) may encourage acceptance of the desired social norm. Further, increasing the visibility of the behaviour in the community ensures that the social norms of an appropriate reference group, the community in which the target audience resides, is promoted. SNA research consistently shows that the impact of SNA campaigns is maximised by using the social norms of an appropriate reference group for the particular target audience (Burchell et al., 2013).

Increasing the visibility of behaviour is a key principle of community-based social marketing (CBSM) (Lynes et al., 2014; McKenzie-Mohr, 2011; McKenzie-Mohr and Schultz, 2014), a form of social marketing that emphasises the role of the community in fostering individual behaviour change (Bryant et al., 2014). CBSM has been applied in several domains. For example, a systematic review of community-based obesity prevention studies using social marketing identified forty-one interventions (Gracia-Marco et al., 2011). Other interventions have targeted pro-environmental behaviours (McKenzie-Mohr, 2000) and early diagnosis of lung cancer (Athey et al., 2011). CBSM principles have also been employed in programmes aiming to increase recycling (Haldeman and Turner, 2009), promote physical activity among youth (Alfonso et al., 2011; McDermott et al., 2010; Nickelson et al., 2011) and condom use among adolescents (Kennedy et al., 2000).

In CBSM, the process of behavioural change is co-produced by an organisation and community, with the community taking the leading role in the delivery of the social marketing programme. The main advantage of a community-based approach is the community's knowledge of local circumstances and needs, which ensures that any available resources are used in the most efficient and effective way, empowering the community in the process of change rather than imposing an expert-driven solution. In CBSM, community members become partners in the intervention's delivery process, and have the power to influence and shape it. Through community involvement, social marketing initiatives can overcome some of the most common barriers to behavioural change, including disengagement with social marketing initiatives and the initial resistance to change (Kennedy, 2010; McKenzie-Mohr and Smith, 1999). 
The success of CBSM is argued to be largely attributable to its ability to translate knowledge into action (Kollmuss and Agyeman, 2002) given its strong basis of procedural theory to guide implementation of programmes (Lynes et al., 2014). CBSM prescribes a fivestage approach to programme design: selecting behaviours, identifying barriers and benefits, developing strategies, conducting a pilot and broad-scale implementation (McKenzie-Mohr, 2011). Recently, understanding of the CBSM approach has been deepened with the identification of 21 principles, including increasing the visibility of the target behaviour and establishing appropriate incentives, which underpin the five stages of CBSM (see Lynes et al., 2014). Increasing the visibility of the target behaviour is a key principle of CBSM strategy on the basis that social diffusion is most likely to occur when the promoted behaviour is visible in the community (McKenzie-Mohr and Schultz, 2014) and developed through direct contact between people rather than campaigns (McKenzie-Mohr, 2011). Little is known, however, about the relationship between the visibility of the target behaviour and the other CBSM principles and programme outcomes (Lynes et al., 2014). This research aims to contribute to addressing this gap by empirically investigating whether application of the CBSM principle of increasing the visibility of a target behaviour through VicHealth’s Walk to School programme can change social norms surrounding walking to and from school.

\section{Method}

\section{Walk to School 2013}

VicHealth has implemented the annual Walk to School programme since 2006. It encourages primary school children to walk to and from school more often during one month in Victoria, Australia. Since 2012, the scope of Walk to School was broadened from a single Walk to School Day to the entire month to increase engagement opportunities, increase the visibility of the programme in the community and facilitate a lasting behavioural change. The Walk to School programme follows the recommendations of Bryant et al. (2014), with VicHealth guiding the design and implementation of the programme, but local councils and schools making many programmatic decisions at the community level. Stakeholders such as councils and schools were provided with resources allowing them to engage caregivers and children. Advertising and media relations at a state wide level, including TV, radio, print and online, were driven by VicHealth and focussed directly on caregivers to encourage participation. Walk to School 2013 was also supported through a dedicated website and smartphone application, Facebook site, Twitter account and information packs for schools, including 
information for newsletters, developed by VicHealth. Other stakeholders, such as CEIPS/Department of Health, MAV, LGPro, Victoria Walks, Heart Foundation and Sun Smart promoted Walk to School via their email databases and e-newsletters. Cotton on Kids was the programme's corporate partner and promoted Walk to School through signage and giveaways at their retail outlets.

In 2013, individuals and schools were encouraged to commit to the programme through the Walk to School website. Incentives supporting participation in the programme were offered. Local councils were offered AUS\$5,000 to AUS\$10,000 grants to promote to, and coordinate the programme for, schools. VicHealth funded 51 councils through the Walk to School grants. VicHealth directly contacted all Victorian primary schools outside funded council areas. In turn, participating schools encouraged primary school aged children (and their caregivers) to walk to and from school. The manner in which walking was promoted by schools varied in line with contextual factors such as the average distance to school and the availability of funding. Some schools, for instance, organised 'walking buses' from landmarks close to the school (e.g. the train station), while others held weekly breakfasts to encourage participation in the programme. Schools were offered prizes for the highest student participation rates. The Walk to School 2013 programme attracted participation from 32,518 primary school students from 303 schools. The total distance walked by all participating students was 411,113 km. All participating students were rewarded for their participation with student certificates and free branded curly shoelaces provided by VicHealth, through the game design of the Walk to School app and weekly competitions that were run throughout the month.

\section{Research Design}

The present research formed part of a larger process and outcome evaluation of Walk to School 2013. Ethics approval for this evaluation was obtained from a university human research ethics committee (Protocol Number MKT/27/13/HREC). This study examined the extent to which Walk to School 2013 changed descriptive and injunctive norms regarding children walking to and from school through a repeated measures quasi-experimental design. This is in line with the call for more rigorous evaluations of social marketing interventions using quasi-experimental and randomised controlled trials (Evans et al., 2014) and specifically, for higher quality study designs and measures to evaluate interventions aiming to increase active transportation to school (Chillón et al., 2011). An online survey was conducted with a non-randomised intervention and control group at three points in time: 
before Walk to School 2013, during Walk to School 2013 (two weeks after commencement of the programme) and 3 months after Walk to School 2013. The link to the survey was disseminated through online advertising via multiple channels, including Facebook and Twitter.

\section{Measures}

The online survey comprised pre-validated scales and open-ended questions, and took approximately 10 minutes to complete. The visibility of walk to school behaviour was not measured directly, that is, respondents were not asked whether they had seen or were aware of children walking to and from school during the programme. This ensured that respondents (who had and had not participated in the Walk to School 2013 programme) were not primed to notice children walking to school (descriptive norms), which would have interfered with the programme effect and the validity of the results reported. Based on participation levels from previous years, it was postulated that a base level of behavioural visibility would occur in most neighbourhoods.

To measure descriptive norms, items were adapted from Rhodes and Courneya (2003). The following four statements were measured on a seven-point scale from strongly disagree to strongly agree: “Many of my [friends'/family members'] children walk to/from school" and "Many of the children in the [neighbourhood/at school] walk to/from school". These four items are internally consistent as evidenced by their Cronbach's Alpha coefficient of .783. The injunctive norms items were adapted from Perugini and Conner (2000). The following three statements were also assessed on a seven-point scale: "People who are important to me think the child should/should not walk to/from school”, "People who are important to me would disapprove/approve of the child walking to/from school", and "People who are important to me want the child to walk to/from school”. The injunctive norms items were also internally consistent with a Cronbach's Alpha coefficient of .883, similar to the .90 reported by Perguini and Conner (2000).

It was important to account for the fact that respondents could have multiple children of primary school age under their care and thus, could have different social norm beliefs for each child depending on factors such as the child's age and gender. Consequently, respondents were asked 'How many children, under your care, attend primary school?’ The survey software then captured the integer provided by the respondent (e.g. 3) and a random number generator populated the following statement: When answering the questions of this survey, please think of child number (e.g. random number between 1 and 3). This approach 
was implemented to avoid the bias that can occur if respondents were asked to think of their oldest child (e.g. social norm perceptions about oldest children may be systematically different to the youngest child).

\section{Sample}

The target population for the survey were caregivers of primary school children, aged between 5-12 years old, who had and had not participated in Walk to School 2013. It was decided to target caregivers, rather than children, given parental control over younger children's transportation to school (Carver et al., 2010). The second online survey established whether respondents' children were participating or not in Walk to School 2013. Caregivers were offered a chance to win one of twenty AUS\$30 vouchers at each time point. The sample size for the full Walk to School 2013 outcome evaluation declined across the three surveys: before Walk to School $2013(\mathrm{n}=512)$, during Walk to School $2013(\mathrm{n}=161)$, and after Walk to School $2013(\mathrm{n}=102)$, representing a retention rate of approximately 19\%. Attrition is common for studies that involve repeated measurements from the same subjects (Little, 1995).

Approximately $86 \%$ of the final sample comprised mothers, representing a skew toward female respondents relative to the Victorian population (Australian Bureau of Statistics, 2013a). They were mostly aged between 35 and 49 years old (83.2\%), which is consistent with the fact that the median age of mothers giving birth is 30.8 (Australian Bureau of Statistics, 2013b). A similar proportion of the sample (56.6\%) relative to the Victorian population (56.1\%) had a post school qualification (Australian Bureau of Statistics, 2013a). Slightly more than half of the respondents reported that their child was seven years or younger (54\%) and male (56\%). Most (74.3\%) respondents reported that their child's school was less than $3 \mathrm{~km}$ from his/her home and that their household owned, on average, one or two cars $(M=1.6, S D=0.6)$. Generally, neither crime $(M=2.6, S D=1.7)$ nor traffic along the route to/from school $(M=4.6, S D=1.9)$ posed a significant concern for caregivers in this sample. A more detailed demographic profile of respondents is shown in Table 1.

When prompted, 67\% of respondents were aware of Walk to School 2013. Of those respondents that were aware of Walk to School 2013, 60\% had a child participating in Walk to School 2013, while 40\% were not participating in the programme. This indicates that some children did not participate in Walk to School 2013 despite their caregivers being aware of the programme. Descriptive and injunctive norms of those aware of Walk to School 2013 were compared to those unaware of the programme using an independent samples $t$-test. Data 
indicated that both injunctive and descriptive norms were not significantly different between those aware of Walk to School 2013 and those unaware at baseline, prior to commencement of the programme. This suggests that the awareness created by promotional materials alone prior to the Walk to School 2013 event where children were encouraged to walk to and school every day did not create divergent social norm perceptions between those caregivers aware of Walk to School 2013 and those not aware of the programme.

[Insert Table 1 about here]

\section{Data Analysis}

A mixed 2 x 3 ANOVA was conducted in SPSS Version 21 to assess whether the injunctive and descriptive norms of respondents that participated in Walk to School 2013 changed significantly over time when compared to respondents that did not participate in Walk to School 2013. The homogeneity of variance, sphericity and equality of error variance assumptions were all met for the mixed design 2 x 3 ANOVA (see Table 2). Following this, $t$-tests and one-way ANOVA's were conducted as post-hoc tests to provide additional insight into the findings. Pairwise deletion was employed to address missing data owing to the relatively small sample size of the study. This technique maximises all data available on an analysis by analysis basis (Marsh, 1998), resulting in some variation in the sample size for each method of analysis.

\section{Results}

This research investigated the impact of the VicHealth's Walk to School 2013 programme on social norms surrounding walking to and from school. The results of the $2 \times 3$ ANOVA, outlined in Table 2, show a significant difference in the descriptive and injunctive norm beliefs of caregivers whose child participated in Walk to School 2013 and those whose child did not participate. Further, caregivers’ perceptions of the descriptive norms surrounding walking to and from school changed significantly over time. However, a change over time was not identified for injunctive norms by this omnibus test. In addition, there was no significant interaction effect between participation and time for injunctive norms, while the interaction was significant only at the $p<.10$ level for descriptive norms. Post-hoc tests, 
specifically t-tests and one-way ANOVA's, were conducted to provide additional insight into these findings.

[Insert Table 2 about here]

Descriptive social norms are defined as the extent to which individuals perceive that others perform a behaviour (Cialdini et al., 1990) and in this study, measure the extent that caregivers of primary school-age children in Victoria, Australia, believe that children of their family members and friends, as well as other children in their neighbourhood, walk to and from school. No significant difference was observed at baseline before the programme commenced in the descriptive norm perceptions of caregivers whose child participated in Walk to School $2013(M=4.5, S D=1.3)$ and caregivers whose child did not $(M=4.2, S D=$ 1.3). During the programme, caregivers whose child participated in Walk to School 2013 reported more positive descriptive norms $(M=4.8, S D=1.4)$ than carers whose child did not $(M=4.1, S D=1.6, t(105)=2.099, p=.038)$. After the programme, the disparity in descriptive norm perceptions between the two groups widened. That is, caregivers whose child participated in Walk to School 2013 reported even more positive descriptive norms ( $M$ $=5.2, S D=1.3)$ than caregivers whose child did not $(M=4.1, S D=1.5), t(63)=3.011, p=$ .004). These results are graphically depicted in Figure 1.

[Insert Figure 1 about here]

There was a significant difference in the descriptive norm beliefs of caregivers whose child participated in Walk to School 2013 over time, $F(2,68)=5.519, p=.006$. Caregivers' perceptions of whether others' children walked to and from school increased significantly (mean difference $=.7, p=.008$ ) from before programme participation to after programme participation (Table 3). In contrast, no significant difference was observed in the descriptive norm beliefs of caregivers whose child did not participate in Walk to School 2013 over time, $F(2,58)=.855, p=.430$.

[Insert Table 3 about here]

Injunctive social norms are defined as individuals' perceptions of whether others approve or disapprove of a behaviour (Cialdini et al., 1990). In other words, in the context of this study, injunctive social norms measure the extent that caregivers of primary school-age 
children in Victoria, Australia, believe that people important to them approve of the walking behaviour and think that their children should walk to and from school. No significant difference was observed at baseline before the programme commenced in the injunctive norm perceptions of caregivers whose child participated in Walk to School 2013 ( $M=4.9, S D=$ $1.5)$ and carers whose child did not $(M=4.4, S D=1.9)$. During the programme, caregivers whose child participated in Walk to School 2013 reported more positive injunctive norms (M $=5.3, S D=1.6)$ than caregivers whose child did not $(M=4.5, S D=1.7, t(102)=2.234, p=$ .028). After the programme, the gap between the two groups also widened. That is, caregivers whose child participated in Walk to School 2013 reported even more positive injunctive norms $(M=5.5, S D=1.5)$ than caregivers whose child did not $(M=4.2, S D=2.0), t(62)=$ $2.950, p=.004$. These results are graphically depicted in Figure 2.

[Insert Figure 2 about here]

There was a significant difference, at the $p<.10$ level, in the injunctive norm beliefs of caregivers whose child participated in Walk to School 2013 over time, $F(2,64)=2.415$, $p$ $=.097$. Caregivers' perception of whether important others would approve of or encourage their child walking to and from school increased significantly (mean difference $=.5, p=$ .045) from prior to participation to during Walk to School 2013 (Table 4). In contrast, no significant difference was observed in the injunctive norm beliefs of caregivers whose child did not participate in Walk to School 2013 over time, $F(2,58)=1.054, p=.355$.

[Insert Table 4 about here]

\section{Theoretical and Practical Implications}

This study shows that increasing the visibility of the target behaviour, a CBSM principle, can influence change in descriptive and injunctive social norms in the context of children walking to and from school. This is an important programme outcome given the established association between social norms and children's walk to and from school behaviour (Schuster et al., in press; Timperio et al., 2006). The results indicate an increase in the extent to which respondents whose child had participated in the programme perceived that (1) others' children were walking to and from school and (2) others approved of this behaviour. This suggests that many caregivers may have been walking with their child and so were exposed 
in a more direct way to other children walking or, at the very least, were primed to take notice of other children walking since their child was participating in the programme. This may have created a shift in norms in the aforementioned group that was not achieved for caregivers who were aware of the campaign, but who were not participating in the programme. This effect could also have been as a result of cognitive dissonance, which outlines that individuals strive for consistency between their beliefs and their behaviours (Festinger, 1962). That is, because their child was participating in the programme, caregivers changed their social norm beliefs to be consistent with this behaviour. Further research could clarify the specific mechanisms of this effect to improve understanding of how behavioural visibility influences social norms.

This study thus provides initial empirical support for the contribution of the CBSM principle of increasing the visibility of the target behaviour to programme outcomes. This extends understanding of the processes through which CBSM affects change, an underresearched domain (Lynes et al., 2014). Future research, however, is needed to test the relative importance of this principle and the other 20 principles of CBSM (Lynes et al., 2014). The results of this study also suggest that the SNA could be enhanced through application of the CBSM principle. That is, traditional media-focused SNA campaigns (e.g. Perkins and Craig, 2002) could be extended with activities designed to increase the visibility of the behaviour in the target audience's community.

Importantly, however, the results also indicate that social marketers should promote participation in programmes such as Walk to School or other means of directing attention to the more visible behaviour. In this study, although respondents who did not participate in the programme were aware of the campaign, without participation in the programme directing their attention to an increased instance of children walking to school, there was no significant change in their social norm perceptions. The full marketing mix, including product, place, price and promotion, can be used to drive participation in the programme (Kubacki et al., 2015). Building on this approach, garnering the support and involvement of influential stakeholders is important to ensuring a holistic and strategic social marketing approach (French and Gordon, 2015) to increasing programme participation. That is, grants offered to councils to promote and coordinate the programme at the local level increased involvement in Walk to School and translated into high participation rates among schools. Participating schools can also be directly incentivised though various prizes to promote walking to school among students. 


\section{Limitations and Future Research}

Nonetheless, this study possesses limitations that provide important directions for future research. First, this quasi-experimental study did not randomly allocate participants to the control or intervention group as it was conducted in a natural, field setting. Future research could therefore reduce potential bias by employing a cluster randomised controlled trial design at the council or school level. A second limitation of the study is its small sample size owing to attrition and conclusions drawn must be considered in light of this limitation. Future studies should attempt to attract larger samples at baseline and provide incentives to reduce attrition rates thereby permitting more rigorous assessment. Third, our research was conducted within six months from the baseline to the final survey (three months after intervention). Longitudinal studies are needed to track long-term changes in social norms as a result of CBSM programmes over two- to five- year periods to ascertain whether changes in social norms are sustained over time. Fourth, the study was conducted in Victoria, Australia, and needs to be replicated in different states across Australia and worldwide to extend our understanding beyond the present sample. Fifth, the current study sought to examine the effect of participation in a CBSM on social norms using an experimental design involving a control group (caregivers whose children did not participate in the intervention), providing an initial understanding at an overall group level. Over 300 schools participated in Walk to School 2013. Multilevel modelling is recommended as an avenue for future research. It would permit examination of activities and consequent visibility of the behaviour (opportunities to witness others walking) at a school level. Additionally, multilevel modelling would extend our understanding of the interplay between participation rates (given that behaviour would have been more visible at those schools where participation rates were higher) and social norms.

Further research is also needed to statistically compare the efficacy of a traditional SNA campaign with a SNA campaign supported by CBSM principles to confirm that CBSM principles can augment the efficacy of social norms approaches. The psychological mechanisms through which the visibility of the behaviour influences social norms were also not examined. Future research, for instance, may focus on the relationship between increased visibility of behaviour and perceived credibility of the social norm it represents to establish whether this mechanism underpins changes in social norms. An alternative mechanism that could be explored is cognitive dissonance as a result of participation in the programme. Further, this research focused exclusively on caregiver perceptions of social norms. Previous 
research shows that both caregiver and child perceptions of social norms are determinants of active transportation to school (Chillón et al., 2014). It would therefore be interesting to examine the relative efficacy of interventions targeting caregiver or child social norms in future research. Last, it is acknowledged that the programme and research adopted a primarily downstream approach to behaviour change, and that the potential of upstream approaches should be investigated as called for by the literature (Hoek and Jones, 2011; Gordon, 2015).

\section{Conclusion}

Social marketing has been identified as potentially promising means to address childhood obesity (Barlovic, 2006; Gracia-Marco et al., 2011), a public health crisis in many countries worldwide (Wang and Lim, 2012). Increasing the physical activity levels of children is one approach to this problem and again, social marketing interventions have been shown to be an important and effective tool in this domain (Kubacki et al., 2015). Little is known, however, about the mechanisms and processes through which behaviour change occurs as a result of social marketing, particularly CBSM, including the relative importance of the principles or benchmark criteria in influencing change (Lynes et al., 2014). The aim of this paper was to investigate the impact of VicHealth’s Walk to School 2013, a CBSM programme, on social norms surrounding children walking to and from school in Victoria, Australia. The study employed a repeated measures quasi-experimental design, in line with the call for more rigorous evaluation of social marketing interventions (Evans et al., 2014), and results indicated that increasing the visibility of walk to school behaviour through participation in the program changed participants' perceptions of the social norms surrounding the behaviour. As such, it provides an important basis for future research aiming to elucidate the manner in which CBSM can effect change for individual and social good in important target audiences and the ways in which CBSM can augment other behaviour change frameworks such as the SNA. 


\section{References}

Alfonso, M., McDermott, R., Thompson, Z., Bryant, C., Courtney, A., Davis, J.L., ... and Jones, J.A. (2011), “Vigorous physical activity among tweens, VERB Summer Scorecard program, Lexington, Kentucky, 2004-2007”, Preventing Chronic Disease, Vol. 8 No. 5, pp. A104.

Athey, V.L., Suckling, R.J., Tod, A.M., Walters, S.J. and Rogers, T.K. (2011), “Early diagnosis of lung cancer: Evaluation of a community-based social marketing intervention”, Thorax, Vol. 77 No. 5, pp. 412-417.

Australian Bureau of Statistics. (2013a), “National Regional Profile: Victoria”, available at: http://www.abs.gov.au/AUSSTATS/abs@nrp.nsf/Previousproducts/2Population/Peopl e12007-2011?opendocument\&tabname=Summary\&prodno=2\&issue=2007-2011 (accessed 6 October 2015).

Australian Bureau of Statistics. (2013b), “3301.0 - Births, Australia, 2013”, available at: http://www.abs.gov.au/ausstats/abs@.nsf/mf/3301.0 (accessed 6 October 2015).

Barlovic, I. (2006), “Obesity, advertising to kids, and social marketing”, Young Consumers, Vol. 7 No. 4, pp. 26-34.

Brophy, S., Cooksey, R., Lyons, R., Thomas, N., Rodgers, S. and Gravenor, M. (2011), "Parental factors associated with walking to school and participation in organised activities at age 5: Analysis of the millennium cohort study”, BMC Public Health, Vol. 11, pp. 14-23.

Bryant, C.A., Courtney, A.H., McDermott, R.J., Lindenberger, J.H., Swanson, M.A., Mayer, ... and Biroscak, B. (2014), “Community-based prevention marketing for policy development: A new planning framework for coalitions”, Social Marketing Quarterly, Vol. 20 No. 4, pp. 219-246.

Burchell, K., Rettie, R. and Patel, K. (2013), "Marketing social norms: Social marketing and the ‘social norm approach””, Journal of Consumer Behaviour, Vol. 12, pp. 1-9.

Carver, A., Timperio, A., Hesketh, K. and Crawford, D. (2010), “Are children and adolescents less active if parents restrict their physical activity and active transport due to perceived risk?”, Social Science and Medicine, Vol. 70, pp. 1799-1805.

Chillón, P., Evenson, K. R., Vaughn, A. and Ward, D. S. (2011), “A systematic review of interventions for promoting active transportation to school”, International Journal Behavioural Nutrition and Physical Activity, Vol. 8 No. 1, pp. 10-27. 
Chillón, P., Hales, D., Vaughn, A., Gizlice, Z., Ni, A. and Ward, D. S. (2014), “A crosssectional study of demographic, environmental and parental barriers to active school travel among children in the United States”, International Journal of Behavioral Nutrition and Physical Activity, Vol. 11, No. 1, pp. 61-71.

Cialdini, R., Reno, R. and Kallgren, C. (1990), “A focus theory of normative conduct: Recycling the concept of norms to reduce littering in public places”, Journal of Personality and Social Psychology, Vol. 58 No. 6, pp. 1015-1026.

Deckelbaum, R.J. and Williams, C.L. (2001), “Childhood obesity: The health issue”, Obesity Research, Vol. 9 Suppl. 4, pp. 239-243.

Department of Health. (2014), “Australia’s physical activity and sedentary behaviour guidelines”, available at: http://www.health.gov.au/internet/main/publishing.nsf/Content/health-pubhlthstrateg-active-evidence.htm (accessed: 3 June 2015).

Evans, W. D., Pattanayak, S. K., Young, S., Buszin, J., Rai, S. and Bihm, J. W. (2014), "Social marketing of water and sanitation products: A systematic review of peerreviewed literature”, Social Science \& Medicine, Vol. 110, pp. 18-25.

Festinger, L. (1962), A Theory of Cognitive Dissonance, Stanford University Press, Stanford, CA.

French, J. and Gordon, R. (2015), Strategic Social Marketing, Sage Publications, London.

Foster, S., Villanueva, K., Wood, L., Christian, H. and Giles-Corti, B. (2014), “The impact of parents' fear of strangers and perceptions of informal social control on children's independent mobility”, Health \& Place, Vol. 26, pp. 60-68.

Gomberg, L., Shari Kessel, S. and Dejong, W. (2001), “Evaluation of a social norms marketing campaign to reduce high-risk drinking at the University of Mississippi”, The American Journal of Drug and Alcohol Abuse, Vol. 27, pp. 375-389.

Gordon, R. (2013), “Unlocking the potential of upstream social marketing”, European Journal of Marketing, 47(9), 1525-1547.

Gracia-Marco, L., Moreno, N.A. and Vicente-Rodriguez, G. (2011), “Impact of social marketing in the prevention of childhood obesity”, Advances in Nutrition, Vol. 3, pp. 6115-6155.

Granfield R. (2002), Can You Believe it? Assessing the Credibility of a Social Norms Campaign. The Report on Social Norms, Paper-Clip Communications, Little Falls, New Jersey. 
Haldeman, T. and Turner, J.W. (2009), "Implementing a community-based social marketing program to increase recycling”, Social Marketing Quarterly, Vol. 15 No. 3, pp. 114127.

Hoek, J., \& Jones, S. C. (2011). Regulation, public health and social marketing: a behaviour change trinity. Journal of Social Marketing, Vol. 1 No. 1, pp. 32-44.

Kallgren, C.A., Reno, R.R. and Cialdini, R. (2000), “A focus theory of normative conduct: when norms do and do not affect behaviour”, Personality and Social Psychology Bulletin, Vol 26 No.8, pp. 1002-1012.

Kennedy, A.L. (2010), “Using community-based social marketing techniques to enhance environmental regulation”, Sustainability, Vol. 2, pp. 1138-1160.

Kennedy, M.G., Mizuno, Y., Seals, B.F., Myllyluoma, J. and Weeks-Norton, K. (2000), "Increasing condom use among adolescents with coalition-based social marketing”, AIDS, Vol. 14 No. 12, pp. 1809-1818.

Kollmuss, A. and Agyeman, J. (2002), "Mind the gap: Why do people act environmentally and what are the barriers to pro-environmental behavior?”, Environmental Education Research, Vol. 8, pp. 239-260.

Kubacki, K., Rundle-Thiele, S., Lahtinen, V. and Parkinson, J. (2015), “A systematic review assessing the extent of social marketing principle use in interventions targeting children (2000-2014)”, Young Consumers, Vol. 16 No. 2, pp. 141-158.

Little, R. (1995), “Modeling the drop-out mechanism in repeated measures studies”, Journal of the American Statistical Association, Vol. 90, pp. 1112-1121.

Lorenc, T., Brunton, G., Oliver, S., Oliver, K. and Oakley, A. (2008), “Attitudes to walking and cycling among children, young people and parents: A systematic review”, Journal of Epidemiology and Community Health, Vol. 62 No.10, pp. 852-857.

Lynes, J., Whitney, S. and Murray, D. (2014), “Developing benchmark criteria for assessing community-based social marketing programs: A look into Jack Johnson’s ‘All at Once’ campaign”, Journal of Social Marketing, Vol. 4 No. 2, pp. 111-132.

Marsh, H.W. (1998), "Pairwise deletion for missing data in structural equation models: Nonpositive definite matrices, parameter estimates, goodness of fit, and adjusted sample sizes”, Structural Equation Modelling: A Multidisciplinary Journal, Vol. 5, pp. 22-36.

Mattern, J.L. and Neighbors, C. (2004), “Social norms campaigns: Examining the relationship between changes in perceived norms and changes in drinking levels”, Journal of Interventions on Alcohol, Vol. 65, pp. 489-493. 
McDermott, R., Davis, J., Bryant, C., Courtney, A. and Alfonso, M. (2010), “Increasing physical activity in children 8 to 12 years old: Experiences with VERB Summer Scorecard”, Perceptual and Motor Skills, Vol. 111, pp. 240-248.

McDonald, N.C. (2007), “Active transportation to school: Trends among U.S. schoolchildren, 1969-2001”, American Journal of Preventative Medicine, Vol. 32 No. 6, pp. 509-516.

McKenzie-Mohr, D. (2000), “New ways to promote proenvironmental behaviour: Promoting sustainable behaviour, an introduction to community-based social marketing”, Journal of Social Issues, Vol. 56, No. 3, pp. 543-554.

McKenzie-Mohr, D. (2011), Fostering Sustainable Behaviour: An Introduction to Community-based Social Marketing ( $3^{\text {rd }}$ ed), New Society Publishers, Canada.

McKenzie-Mohr, D. and Schultz, W. (2014), “Choosing effective behaviour change tools”, Social Marketing Quarterly, Vol. 20, pp. 35-46.

McKenzie-Mohr, D. and Smith, W. (1999), Fostering Sustainable Behavior: An Introduction to Community-Based Social Marketing, New Society Publishers, Gabriola Island, BC, USA.

McMillan, T.E. (2007), “The relative influence of urban form on a child's travel mode to school”, Transportation Research Part A, Vol. 41 No.1, pp. 69-79.

Murphy, S., Moore, G., Williams, A. and Moore, L. (2012), “An exploratory cluster randomised trial of a university halls of residence based social norms intervention in Wales, UK”, BMC Public Health, Vol. 12, pp. 186.

Nickelson, J., Alfonso, M.L., McDermott, R., Bumpus, E.C., Bryant, C.A. and Baldwin, J.A. (2011), “Characteristics of ‘tween’ participants and non-participants in the VERB Summer Scorecard physical activity promotion program”, Health Education Research, Vol. 26, pp. 225-238.

Panter, J. R., Jones, A. P., Van Sluijs, E. M. and Griffin, S. J. (2010), “Attitudes, social support and environmental perceptions as predictors of active commuting behaviour in school children”, Journal of Epidemiology and Community Health, Vol. 64 No. 1, pp. 41-48.

Perkins H.W. and Craig, D.W. (2002), A Multifaceted Social Norms Approach to Reduce High-risk Drinking: Lessons from Hobart and William Smith Colleges, The Higher Education Center for Alcohol and Other Drug Prevention and the U.S. Department of Education, Newton, MA. 
Perugini, M. and Conner, M. (2000), "Predicting and understanding behavioural volitions: The interplay between goals and behaviours”, European Journal of Social Psychology, Vol. 30, pp.705-731.

Reynolds, R., McKenzie, S., Allender, S., Brown, K., \& Foulkes, C. (2014), “Systematic review of incidental physical activity community interventions”, Preventive Medicine, Vol. 67, 46-64.

Rhodes, R.E. and Courneya, K S. (2003), “Investigating multiple components of attitude, subjective norm, and perceived behavioural control: An examination of the theory of planned behaviour in the exercise domain”, The British Journal of Social Psychology, Vol. 42, pp. 129-146.

Rosenberg, D., Sallis, J., Conway, T., Cain, K. and McKenzie, T. (2006), “Active transportation to school over 2 years in relation to weight status and physical activity”, Obesity, Vol. 14 No. 10, pp. 1771-1776.

Ross, L., Green, D. and House, P. (1977), “The 'false consensus effect': An egocentric bias in social perception and attribution processes”, Journal of Experimental Social Psychology, Vol. 13, pp. 279-301.

Schultz, W., Nolan, J., Cialdini, R., Goldstein, N. and Griskevicius, V. (2007), “The constructive, destructive, and reconstructive power of social norms”, Psychological Science, Vol. 18 No. 5, pp. 429-434.

Schuster, L., Kubacki, K., and Rundle-Thiele, S. (in press), “Understanding caregivers' intentions for their child to walk to school: Further application of the theory of planned behaviour”, Health Marketing Quarterly, Vol. 33 No. 4.

Shonkoff, J.P., Boyce, W.T. and McEwen, B.S. (2009), “Neuroscience, molecular biology, and the childhood roots of health disparities: Building a new framework for health promotion and disease prevention”, Jama, Vol. 301 No. 21, pp. 2252-2259.

Thaler, R.H. and Sunstein, C.R. (2008), Nudge: Improving Decisions about Health, Wealth and Happiness, Yale University Press, London, UK.

Thombs, D. L., Dotterer, S., Olds, R. S., Sharp, K. E. and Raub, C. G. (2004), “A close look at why one social norms campaign did not reduce student drinking”, Journal of American College Health, Vol. 53 No. 2, pp. 61-68.

Timperio, A., Ball, K., Salmon, J., Roberts, R., Giles-Corti, B., Simmons, D., Baur, L.A. and Crawford, D. (2006), "Personal, family, social, and environmental correlates of active commuting to school”, American Journal of Preventative Medicine, Vol. 30 No. 1, pp. 45-51. 
Troiani, V., Peelle, J. E., Clark, R. and Grossman, M. (2009), "Is it logical to count on quantifiers? Dissociable neural networks underlying numerical and logical quantifiers”, Neuropsychologia, Vol. 47 No. 1, pp. 104-111.

van der Ploeg, H.P., Merom, D., Corpuz, G. and Bauman, A. (2008), “Trends in Australian children traveling to school 1971-2003: Burning petrol or carbohydrates?”, Preventative Medicine, Vol. 46 No. 1, pp. 60-62.

Wang, Y. and Lim, H. (2012), “The global childhood obesity epidemic and the association between socio-economic status and childhood obesity”, International Review of Psychiatry, Vol. 24 No. 3, pp. 176-188.

WHO. (2015), “Physical activity and young people”, available at: http://www.who.int/dietphysicalactivity/factsheet_young_people/en/ (accessed 3 June 2015). 